\title{
Efficacy and safety of two doses of budesonide/formoterol fumarate metered dose inhaler in COPD
}

\author{
Nicola A. Hanania ${ }^{1}$, Alberto Papi $\mathbb{1}^{2}$, Antonio Anzueto ${ }^{3}$, Fernando J. Martinez ${ }^{4}$, \\ Kimberly A. Rossman ${ }^{5}$, Christy S. Cappelletti ${ }^{6}$, Elizabeth A. Duncan ${ }^{6}$, \\ Jack S. Nyberg ${ }^{7}$ and Paul M. Dorinsky ${ }^{6}$
}

Affiliations: 'Section of Pulmonary and Critical Care Medicine, Baylor College of Medicine, Houston, TX, USA ${ }^{2}$ Research Centre on Asthma and COPD, Dept of Medical Sciences, University of Ferrara, Ferrara, Italy. ${ }^{3}$ Pulmonary Medicine and Critical Care, University of Texas Health Science Center and South Texas Veterans Health Care System, San Antonio, TX, USA. ${ }^{4}$ Joan and Sanford I. Weill Dept of Medicine, Weill Cornell Medicine, New York, NY, USA. ${ }^{5}$ AstraZeneca, Morristown, NJ, USA. ${ }^{6}$ AstraZeneca, Durham, NC, USA. ${ }^{7}$ Former employee of AstraZeneca, Morristown, NJ, USA.

Correspondence: Nicola Hanania, Section of Pulmonary and Critical Care Medicine, Baylor College of Medicine, Houston, TX 77030, USA. E-mail: hananialabcm.edu

ABSTRACT Inhaled corticosteroid/long-acting $\beta_{2}$-agonist combination therapy is a recommended treatment option for patients with chronic obstructive pulmonary disease (COPD) and increased exacerbation risk, particularly those with elevated blood eosinophil levels. SOPHOS (NCT02727660) evaluated the efficacy and safety of two doses of budesonide/formoterol fumarate dihydrate metered dose inhaler (BFF MDI) versus formoterol fumarate dihydrate (FF) MDI, each delivered using co-suspension delivery technology, in patients with moderate-to-very severe COPD and a history of exacerbations.

In this phase 3, randomised, double-blind, parallel-group, 12-52-week, variable length study, patients received twice-daily BFF MDI $320 / 10 \mu \mathrm{g}$ or $160 / 10 \mu \mathrm{g}$, or FF MDI $10 \mu \mathrm{g}$. The primary endpoint was change from baseline in morning pre-dose trough forced expiratory volume in $1 \mathrm{~s}\left(\mathrm{FEV}_{1}\right)$ at week 12. Secondary and other endpoints included assessments of moderate/severe COPD exacerbations and safety.

The primary analysis (modified intent-to-treat) population included 1843 patients (BFF MDI 320/10 $\mu \mathrm{g}$, $\mathrm{n}=619$; BFF MDI 160/10 $\mu \mathrm{g}, \mathrm{n}=617$; and FF MDI, $\mathrm{n}=607$ ). BFF MDI 320/10 $\mu \mathrm{g}$ and 160/10 $\mu \mathrm{g}$ improved morning pre-dose trough $\mathrm{FEV}_{1}$ at week 12 versus $\mathrm{FF}$ MDI (least squares mean differences $34 \mathrm{~mL}$ $[\mathrm{p}=0.0081]$ and $32 \mathrm{~mL}[\mathrm{p}=0.0134]$, respectively), increased time to first exacerbation (hazard ratios 0.827 $[\mathrm{p}=0.0441]$ and $0.803[\mathrm{p}=0.0198]$, respectively) and reduced exacerbation rate (rate ratios 0.67 [ $\mathrm{p}=0.0001]$ and 0.71 [ $\mathrm{p}=0.0010]$, respectively). Lung function and exacerbation benefits were driven by patients with blood eosinophil counts $\geqslant 150$ cells $\cdot \mathrm{mm}^{-3}$. The incidence of adverse events was similar, and pneumonia rates were low $(\leqslant 2.4 \%)$ across treatments.

SOPHOS demonstrated the efficacy and tolerability of BFF MDI 320/10 $\mu \mathrm{g}$ and $160 / 10 \mu \mathrm{g}$ in patients with moderate-to-very severe COPD at increased risk of exacerbations.

@ERSpublications

Co-suspension delivery technology budesonide/formoterol fumarate metered dose inhaler improve lung function and reduce exacerbation risk versus LABA monotherapy in patients with moderate to very severe COPD and an exacerbation history in the prior year http://bit.ly/3aDOvru

Cite this article as: Hanania NA, Papi A, Anzueto A, et al. Efficacy and safety of two doses of budesonide/formoterol fumarate metered dose inhaler in COPD. ERJ Open Res 2020; 6: 00187-2019 [https://doi.org/10.1183/23120541.00187-2019].

This article has supplementary material available from openres.ersjournals.com

This study is registered at www.clinicaltrials.gov with identifier number NCT02727660. Data underlying the findings described in this manuscript may be obtained in accordance with AstraZeneca's data sharing policy described at https:// astrazenecagrouptrials.pharmacm.com/ST/Submission/Disclosure.

Received: 26 July 2019 | Accepted after revision: 19 Jan 2020

Copyright $\odot$ ERS 2020. This article is open access and distributed under the terms of the Creative Commons Attribution Licence 4.0. 


\section{Introduction}

The Global Initiative for Chronic Obstructive Lung Disease (GOLD) recommends the use of an inhaled corticosteroid (ICS) as an add-on treatment with a long-acting $\beta_{2}$-agonist (LABA) for patients with chronic obstructive pulmonary disease (COPD) who experience exacerbations despite long-acting bronchodilator monotherapy; particularly when they have elevated blood eosinophil levels [1]. Clinical studies have demonstrated that ICS/LABA combination therapy can improve lung function and reduce COPD exacerbation rates more effectively than LABA monotherapy [2-11].

The budesonide/formoterol fumarate dihydrate metered dose inhaler (BFF MDI) is an ICS/LABA fixed-dose combination that is formulated using innovative co-suspension delivery technology. Unlike drug crystal-only suspensions, co-suspension delivery technology enables reliable aerosol performance and consistent drug delivery, even in the presence of simulated patient-handling errors $[12,13]$.

The recently completed phase 3 TELOS study (NCT02766608), conducted in patients with moderate-to-very severe COPD who were not required to have an exacerbation history, demonstrated that BFF MDI $320 / 10 \mu \mathrm{g}$ and $160 / 10 \mu \mathrm{g}$ improved lung function over 24 weeks compared with ICS monotherapy (which is not a recommended therapy for COPD) and reduced COPD exacerbations compared with LABA monotherapy. There was a numerical dose response favouring the BFF MDI $320 / 10 \mu \mathrm{g}$ dose for all lung function and exacerbation endpoints [11].

The current SOPHOS study (NCT02727660) evaluated lung function (primary objective), COPD exacerbations (secondary objectives) and safety, following treatment with BFF MDI 320/10 $\mu$ g, BFF MDI $160 / 10 \mu \mathrm{g}$ or formoterol fumarate dihydrate (FF) MDI monotherapy for at least 12 , and up to 52, weeks in patients with moderate-to-very severe COPD who had a documented history of at least one moderate/ severe COPD exacerbation in the previous 12 months.

\section{Material and methods}

\section{Patients}

Patients (40-80 years of age) were current/former smokers ( $\geqslant 10$ pack-years) with a history of COPD (defined by American Thoracic Society/European Respiratory Society or locally applicable guidelines) [14] who remained symptomatic (COPD Assessment Test score $\geqslant 10$ ) despite receiving one or more inhaled maintenance bronchodilators. Patients were required to have a post-bronchodilator forced expiratory volume in $1 \mathrm{~s}\left(\mathrm{FEV}_{1}\right) /$ forced vital capacity ratio $<0.70$, and post-bronchodilator $\mathrm{FEV}_{1} \geqslant 25 \%$ to $<80 \%$ predicted normal (second screening visit) according to the National Health and Nutrition Examination Survey III reference equations $[15,16]$. Patients had a documented history of at least one moderate/severe COPD exacerbation in the previous 12 months. Patients with a current diagnosis of asthma were excluded.

\section{Study design}

In this double-blind, parallel-group study, patients were screened at 292 centres in 18 countries, and randomised 1:1:1 using an interactive web response system to receive twice-daily BFF MDI 320/10 $\mu$, BFF MDI $160 / 10 \mu \mathrm{g}$ or FF MDI $10 \mu \mathrm{g}$ (figure E1). Randomisation was stratified by country, exacerbation history, post-bronchodilator $\mathrm{FEV}_{1}$ and blood eosinophil count (with enrolment targeted at a 2:1 ratio of patients with eosinophil counts $\geqslant 150$ and $<150$ cells $\cdot \mathrm{mm}^{-3}$ ).

Prohibited COPD medications, which included long-acting muscarinic antagonists (LAMAs) and LABAs (see online data supplement), were discontinued at the start of screening. Patients receiving maintenance ICS (single inhaler or ICS/LABA) continued the ICS component of treatment throughout the screening period and discontinued the ICS component at randomisation. Albuterol sulfate (Ventolin HFA; GlaxoSmithKline, Research Triangle Park, NC, USA) was provided as rescue medication throughout the study.

Patients received 12 to 52 weeks of treatment. The study ended when the last patient remaining in the study completed 12 weeks of treatment or completed their final visit.

The study adhered to the Declaration of Helsinki, the International Council for Harmonisation/Good Clinical Practice and applicable regulatory requirements. Patients provided written informed consent. Informed consent forms were reviewed and approved by an Independent Ethics Committee or Institutional Review Board.

\section{Efficacy endpoints and assessments}

Efficacy analyses were based on the modified intent-to-treat (mITT) population (data from all patients who received any amount of the study drug collected before treatment discontinuation). Endpoints and statistical analysis approaches differed depending on regional regulatory requirements. This manuscript describes the analysis using the US approach. Further details of study estimands, analysis populations, statistical analyses, sample size calculations, definitions of COPD exacerbations and severity, the analysis using the Ex-US approach, and post hoc and subgroup analyses are provided in the online data supplement. 
The primary endpoint (US registration approach) was the change from baseline in morning pre-dose trough $\mathrm{FEV}_{1}$ at week 12, analysed using the efficacy estimand. Analysis of the same outcome using an attributable estimand was the first secondary endpoint.

Further secondary endpoints were: time to first moderate/severe COPD exacerbation; change from baseline in average daily rescue medication use over 12 weeks; and St George's Respiratory Questionnaire (SGRQ) responder rate (percentage of patients achieving a minimal clinically important difference $\geqslant 4$ units in total score) at week 12. The rates of moderate/severe exacerbations were also assessed.

Pre-specified subgroup analyses of the primary endpoint and exacerbation rates were performed according to baseline blood eosinophil count $\left(<150\right.$ versus $\geqslant 150$ cells $\left.\cdot \mathrm{mm}^{-3}\right)$ and according to number of moderate/ severe COPD exacerbations in the previous 12 months (1 versus $\geqslant 2$ ). Additional post hoc analyses of exacerbation rates by ICS use at baseline and by 4 -week intervals were also performed.

\section{Safety analyses}

Treatment-emergent adverse events (TEAEs) were monitored in the safety population (all randomised patients who received study drug, even if $<1$ full dose). Potential major adverse cardiovascular events (MACE) and pneumonia cases were adjudicated by an external Clinical Endpoint Committee.

\section{Results}

\section{Study population}

The first patient was randomised in May 2016, and the study completed in April 2018. Of 1876 randomised patients, 1864 (99.4\%) were treated (BFF MDI 320/10 $\mu \mathrm{g}, \mathrm{n}=624$; BFF MDI 160/10 $\mu \mathrm{g}, \mathrm{n}=627$; and FF MDI, $\mathrm{n}=613)$, and 1843 (98.2\%) were included in both the mITT and safety populations; A total of 1585 (84.5\%) patients completed the study (fig. 1). Overall, 1625 (86.6\%), 1123 (59.9\%) and

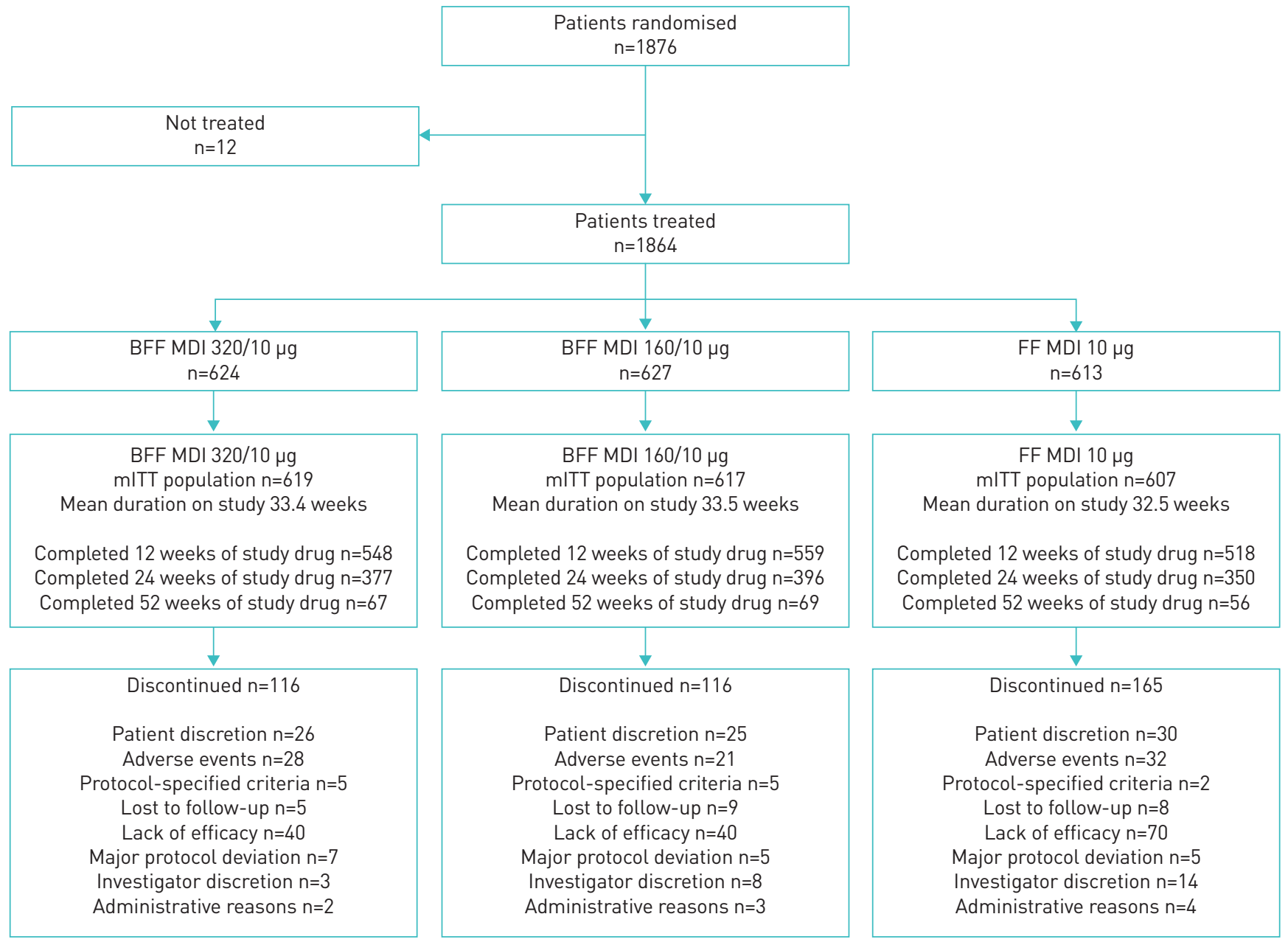

FIGURE 1 Patient disposition. A total of 21 subjects had participated in multiple sponsor studies and were excluded from the intent to treat (ITT), modified ITT (mITT) and safety populations. BFF: budesonide/formoterol fumarate dihydrate; MDI: metered dose inhaler; FF: formoterol fumarate dihydrate. 
TABLE 1 Demographics and baseline characteristics (modified intent-to-treat population)

\begin{tabular}{|c|c|c|c|c|}
\hline & BFF MDI $320 / 10 \mu \mathrm{g}$ & BFF MDI $160 / 10 \mu g$ & FF MDI $10 \mu \mathrm{g}$ & All patients \\
\hline Patients, $\mathrm{n}$ & 619 & 617 & 607 & 1843 \\
\hline Age, years & $65.3 \pm 8.1$ & $64.5 \pm 8.4$ & $64.8 \pm 8.5$ & $64.9 \pm 8.3$ \\
\hline Male & $367(59.3)$ & $345(55.9)$ & $339(55.8)$ & $1051(57.0)$ \\
\hline White/black/other, \% & $83.0 / 4.8 / 12.1$ & $83.6 / 3.6 / 12.8$ & $83.0 / 4.8 / 12.2$ & $83.2 / 4.4 / 12.4$ \\
\hline Current smoker & $257(41.5)$ & $223(36.1)$ & $245(40.4)$ & 725 (39.3) \\
\hline SGRQ total score & $51.4 \pm 18.2$ & $51.1 \pm 17.8$ & $50.7 \pm 17.6$ & $51.1 \pm 17.8$ \\
\hline \multicolumn{5}{|l|}{ History of moderate/severe exacerbations } \\
\hline 0 exacerbations & $5(0.8)$ & 2 (0.3) & $1(0.2)$ & $8(0.4)$ \\
\hline 1 exacerbation & $378(61.1)$ & $374(60.6)$ & $374(61.6)$ & $1126(61.1)$ \\
\hline$\geqslant 2$ exacerbations & $236(38.1)$ & $241(39.1)$ & $232(38.2)$ & 709 (38.5) \\
\hline \multicolumn{5}{|l|}{ History of severe exacerbations } \\
\hline Mild & $0(0.0)$ & $1(0.2)$ & $1(0.2)$ & $2(0.1)$ \\
\hline Moderate & $338(54.6)$ & $330(53.5)$ & $321(52.9)$ & 989 (53.7) \\
\hline Severe & $241(38.9)$ & 230 (37.3) & $244(40.2)$ & 715 (38.8) \\
\hline Very severe & $37(6.0)$ & $56(9.1)$ & $36(5.9)$ & $129(7.0)$ \\
\hline COPD duration, years & $8.1 \pm 6.4$ & $7.7 \pm 5.5$ & $7.9 \pm 6.2$ & $7.9 \pm 6.1$ \\
\hline \multicolumn{5}{|l|}{ Prior COPD treatment ${ }^{\pi}$} \\
\hline SABA and/or SAMA only, PRN & $4(0.6)$ & $3(0.5)$ & $1(0.2)$ & $8(0.4)$ \\
\hline MA only & $26(4.2)$ & $33(5.3)$ & $30(4.9)$ & $89(4.8)$ \\
\hline BA only & $22(3.6)$ & $37(6.0)$ & $39(6.4)$ & $98(5.3)$ \\
\hline ICS only & $12(1.9)$ & $14(2.3)$ & $13(2.1)$ & $39(2.1)$ \\
\hline MA/BA only & $83(13.4)$ & $81(13.1)$ & $71(11.7)$ & $235(12.8)$ \\
\hline ICS/BA only & $272(43.9)$ & $264(42.8)$ & $258(42.5)$ & $794(43.1)$ \\
\hline ICS/MA only & $13(2.1)$ & $16(2.6)$ & $17(2.8)$ & $46(2.5)$ \\
\hline \multicolumn{5}{|c|}{ 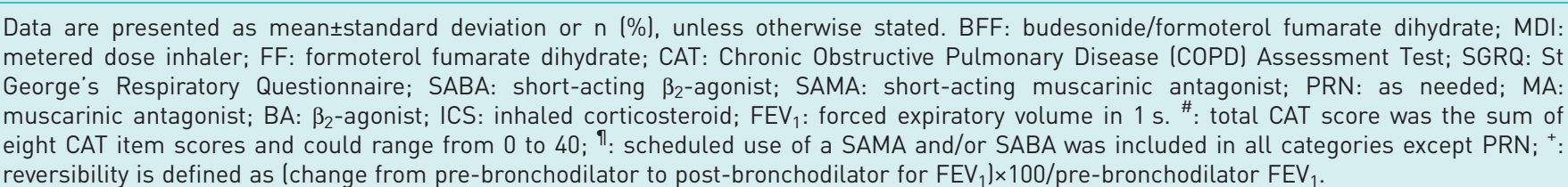 } \\
\hline
\end{tabular}

$192(10.2 \%)$ patients completed 12, 24 and 52 weeks of treatment, respectively. The mean study duration was 232.1 days (33.2 weeks). Reasons for study discontinuation are summarised in figure 1 .

Demographic characteristics were generally balanced across treatment groups (table 1). Most patients in the mITT population were white $(83.2 \%)$ and male $(57.0 \%)$. The mean \pm standard deviation age was $64.9 \pm 8.3$ years, $39.3 \%$ of patients were current smokers and the mean \pm sD smoking history was $45.0 \pm 27.1$ pack-years. Most patients (76.3\%) used ICS at screening. Enrolment had been targeted to achieve a 2:1 ratio for eosinophil subgroups ( $\geqslant 150$ versus $<150$ cells $\cdot \mathrm{mm}^{-3}$ ) and, accordingly, $67.2 \%$ of patients had a baseline blood eosinophil count of $\geqslant 150$ cells $\cdot \mathrm{mm}^{-3}$ (figure E2). In the 12 months before screening, $38.5 \%$ of patients had two or more moderate/severe exacerbations.

\section{Efficacy analyses}

For the primary endpoint of change from baseline in morning pre-dose trough $\mathrm{FEV}_{1}$ at week 12, analysed using the efficacy estimand, BFF MDI $320 / 10 \mu \mathrm{g}$ and $160 / 10 \mu \mathrm{g}$ demonstrated statistically significant 
improvements versus FF MDI, with least squares mean (LSM) differences of $34 \mathrm{~mL}$ (95\% confidence interval [CI] 9-60; $\mathrm{p}=0.0081$ ) and $32 \mathrm{~mL}$ [95\% CI 7-57; $\mathrm{p}=0.0134]$, respectively (table 2 and fig. 2). Analysis of the same endpoint for the attributable estimand (secondary analysis) also demonstrated significant improvements for BFF MDI 320/10 $\mu \mathrm{g}$ and 160/10 $\mu \mathrm{g}$ versus FF MDI (LSM differences $50 \mathrm{~mL}$ [95\% CI 24-76, p=0.0002] and $44 \mathrm{~mL}$ [95\% CI 18-70; $\mathrm{p}=0.0009]$, respectively) (table 2).

The time to first moderate/severe COPD exacerbation was significantly longer for BFF MDI 320/10 $\mu \mathrm{g}$ and BFF MDI 160/10 $\mu$ g versus FF MDI (hazard ratio [HR] 0.827 [95\% CI 0.688-0.995; $\mathrm{p}=0.0441$ ] and 0.803 [95\% CI 0.668-0.966; $\mathrm{p}=0.0198$ ], respectively) (table 2), with the benefits for both BFF MDI doses versus FF MDI evident from as early as 4 weeks and throughout the treatment period (fig. 3). In the subgroup of patients with a history of at least two moderate/severe exacerbations in the last 12 months, BFF MDI 320/ $10 \mu \mathrm{g}(\mathrm{n}=236)$ and $160 / 10 \mu \mathrm{g}(\mathrm{n}=241)$ delayed the time to first exacerbation versus FF MDI $(\mathrm{n}=232)$ to a similar extent compared with the overall population. However, treatment differences did not reach statistical significance in this smaller patient sample (HR 0.783 [95\% CI 0.590-1.039; p=0.0904] and 0.799 [95\% CI 0.603-1.059; $\mathrm{p}=0.1178$ ], respectively).

BFF MDI 320/10 $\mu \mathrm{g}$ and $160 / 10 \mu \mathrm{g}$ reduced the rate of moderate/severe COPD exacerbations versus $\mathrm{FF}$ MDI (rate ratios 0.67 [95\% CI 0.54-0.82; $\mathrm{p}=0.0001$ ] and 0.71 [95\% CI 0.58-0.87; $\mathrm{p}=0.0010$ ], respectively;

\section{TABLE 2 Primary, secondary and additional efficacy endpoints (modified intent-to-treat population; efficacy estimand unless} stated otherwise)

BFF MDI $320 / 10 \mu g$

619

Patients, $n$

Primary endpoint

Change from baseline in morning pre-dose trough $\mathrm{FEV}_{1}(\mathrm{~mL})$ at week $12^{\#}$ $\mathrm{n}$

$\mathrm{LSM} \pm \mathrm{SE}$

LSM difference versus FF MDI (95\% CI) p-value

Secondary endpoints

Change from baseline in morning pre-dose trough $\mathrm{FEV}_{1}(\mathrm{~mL})$ at week 12 (attributable estimand) ${ }^{\#}$

$L S M \pm S E$

LSM difference versus FF MDI $(95 \% \mathrm{CI})$ p-value

Time to first moderate/severe COPD exacerbation ${ }^{\text {? }}$

Patients with exacerbation $\mathrm{n}(\%)$

$\mathrm{HR}$ versus FF MDI $(95 \% \mathrm{Cl})$

p-value

SGRQ responder rate at week 12

Responders $\mathrm{n}[\%]$

Difference versus FF MDI \% $(95 \% \mathrm{CI})$

p-value
Change from baseline in mean daily rescue medication use (puffs day $^{-1}$ ) over 12 weeks $^{\#}$

n

$L S M \pm S E$

LSM difference versus FF MDI (95\% CI) p-value

\section{Additional endpoints}

Rate of moderate/severe exacerbations per year ${ }^{\S}$

Adjusted rate of exacerbations+/-SE

Rate ratio versus FF MDI $(95 \% \mathrm{CI})$

p-value

542

$72 \pm 9.4$

$34(9-60)$

0.0081

612

$59 \pm 9.7$

$50(24-76)$

0.0002

220 (35.5)

$0.827(0.688-0.995)$

0.0441

$315(51.98)$

7.55 (1.67-13.43)

0.0121

612

$-0.9 \pm 0.09$

$-0.32(-0.56$ to -0.08$)$

0.0097

$0.93 \pm 0.073$

$0.67(0.54-0.82)$ $0.0001^{f}$

Time to first moderate/severe COPD exacerbation in patients with a history

Patients with exacerbation, $\mathrm{n}(\%)$

$\mathrm{HR}$ versus FF MDI (95\% Cl)

p-value

$93[39.4)$

$0.783(0.590-1.039$

0.0904
BFF MDI $160 / 10 \mu \mathrm{g}$

617

540

$69 \pm 9.3$

$32(7-57)$

0.0134
FF MDI $10 \mu g$

607

501

$37 \pm 9.6$

612

$53 \pm 9.5$

601

$44(18-70)$

0.0009

223 (36.1)

241 (39.7)

$0.803(0.668-0.966)$

0.0198

331 (54.00)

11.05 (5.18-16.91)

0.0002

610

$-0.9 \pm 0.09$

$-0.29(-0.53$ to -0.05$)$

0.0185

$0.98 \pm 0.076$

$0.71(0.58-0.87)$

$0.0010^{f}$

ions in the last 12 months $^{\S}$

97 (40.2)

0.799 (0.603-1.059)

0.1178
599

$-0.6 \pm 0.09$

$262(43.96)$

$1.39 \pm 0.106$

$106(45.7)$

BFF: budesonide/formoterol fumarate dihydrate; MDI: metered dose inhaler; FF: formoterol fumarate dihydrate; FEV ${ }_{1}$ : forced expiratory volume in $1 \mathrm{~s}$; LSM: least squares mean; HR: hazard ratio; SGRQ: St George's Respiratory Questionnaire; COPD: chronic obstructive pulmonary disease. \#: analysed by repeated measures linear mixed model; १: analysed by Cox regression; ${ }^{+}$: analysed by logistic regression model; $\S$ : analysed by negative binomial regression. Rate of exacerbations per year=total number of exacerbations / total years of exposure across all patients for the treatment. $f$ : $p$-values for this endpoint are considered nominal since these analyses were not under Type I error control. 


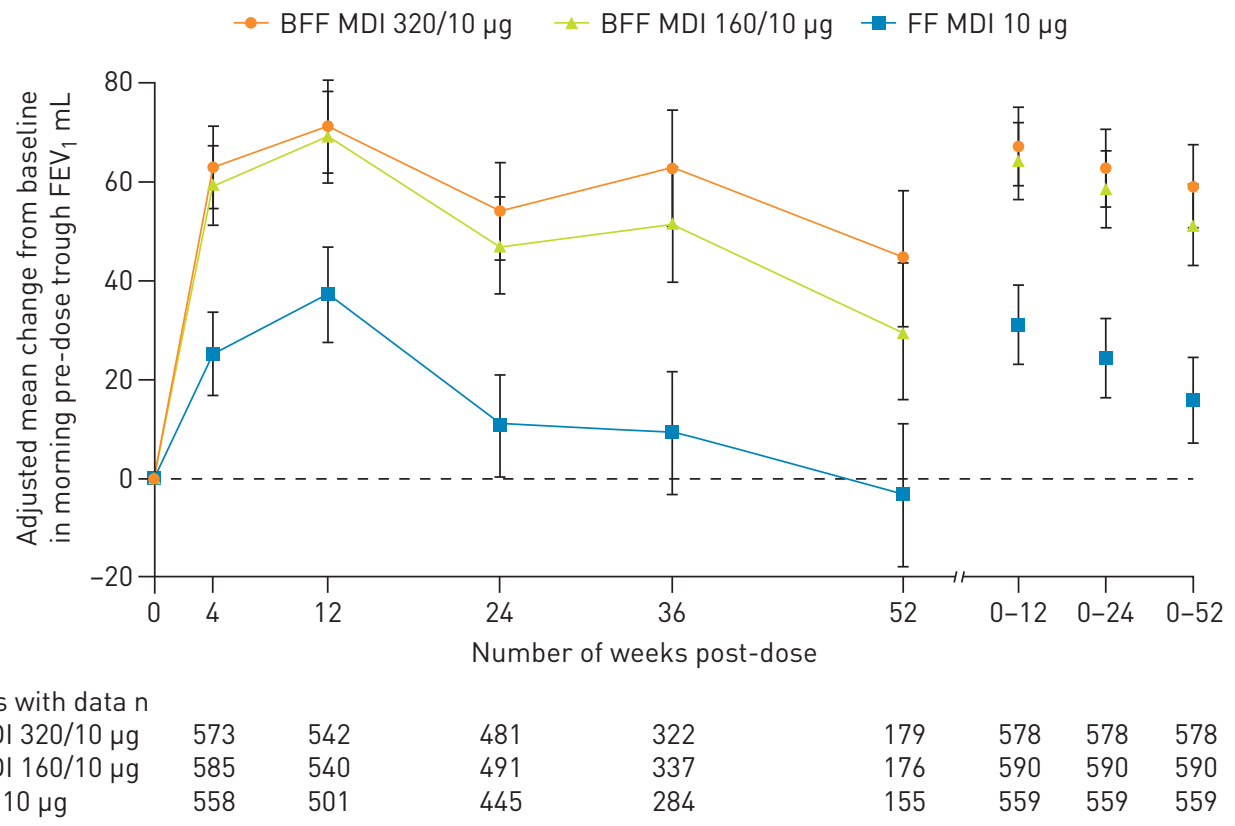

FIGURE 2 Primary efficacy endpoint: adjusted mean change from baseline in morning pre-dose trough forced expiratory volume in $1 \mathrm{~s}\left(\mathrm{FEV}_{1}\right)$ over time (modified intent-to-treat population; efficacy estimand). Error bars represent the standard error. BFF: budesonide/formoterol fumarate dihydrate; MDI: metered dose inhaler; FF: formoterol fumarate dihydrate.

these endpoints were not included in the Type I error control strategy, so were nominally significant) (table 2).

Both BFF MDI doses significantly reduced mean daily rescue medication use over 12 weeks and significantly increased SGRQ responder rates at week 12 versus treatment with FF MDI alone (table 2).

Patients at risk $\mathrm{n}$ BFF MDI 320/10 $\mu$ BFF MDI 160/10 $\mu \mathrm{g}$ FF MDI $10 \mu \mathrm{g}$

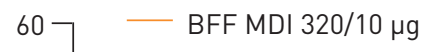
estimand). BFF: budesonide/formoterol fumarate dihydrate; MDI: metered dose inhaler; FF: formoterol fumarate dihydrate. 
a)

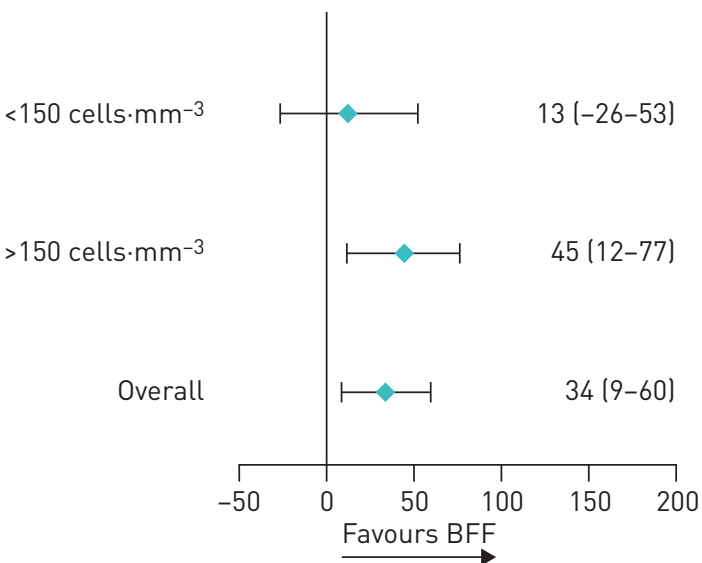

BFF MDI 160/10 $\mu \mathrm{g}$ versus FF MDI $10 \mu \mathrm{g}$

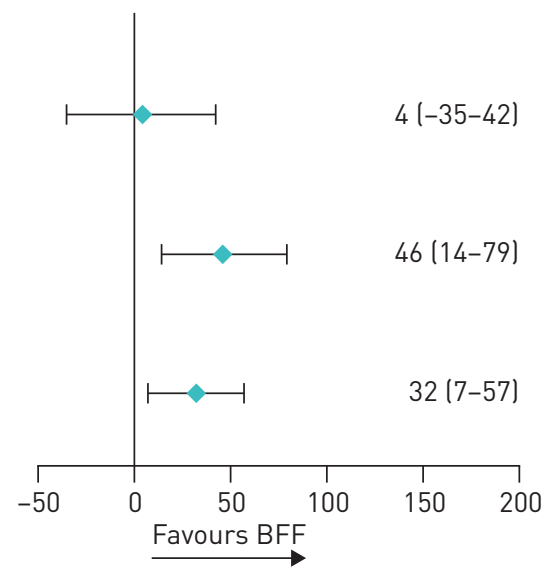

Adjusted mean difference $\mathrm{mL}$

b) BFF MDI 320/10 $\mu \mathrm{g}$ versus FF MDI $10 \mu \mathrm{g}$

BFF MDI 160/10 $\mu$ g versus FF MDI $10 \mu \mathrm{g}$

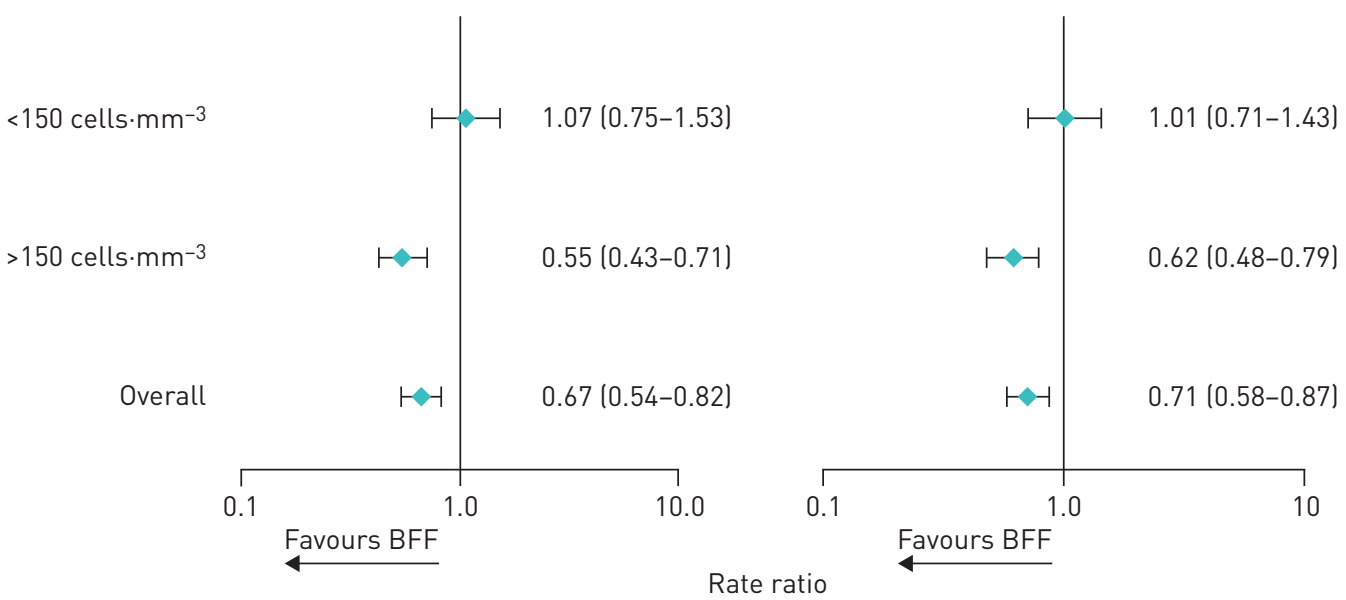

FIGURE 4 Change from baseline in morning pre-dose trough forced expiratory volume in $1 \mathrm{~s}\left(\mathrm{FEV}_{1}\right)$ at week 12 , a) and rate of moderate/severe chronic obstructive pulmonary disease (COPD) exacerbations, b) by baseline eosinophil count (modified intent-to-treat population; efficacy estimand). Error bars represent $95 \%$ confidence intervals. BFF: budesonide/formoterol fumarate dihydrate; MDI: metered dose inhaler; FF: formoterol fumarate dihydrate.

Pre-specified subgroup analyses suggested that the improvements in morning pre-dose trough $\mathrm{FEV}_{1}$ at week 12 and reductions in the rate of moderate/severe COPD exacerbations with both doses of BFF MDI compared with FF MDI were driven by patients with a baseline blood eosinophil count $\geqslant 150$ cells $\cdot \mathrm{mm}^{-3}$ (fig. 4). Further analysis of lung function response by continuous baseline eosinophil count with locally weighted scatterplot smoothing (LOESS) curves showed that improvements in morning pre-dose trough $\mathrm{FEV}_{1}$ for BFF MDI 320/10 $\mu \mathrm{g}$ versus FF MDI at week 12 began at blood eosinophil levels of approximately 100-150 cells $\cdot \mathrm{mm}^{-3}$. Results for BFF MDI 160/10 $\mu \mathrm{g}$ versus FF MDI were consistent with these findings up to eosinophil counts of approximately 350 cells $\cdot \mathrm{mm}^{-3}$, after which improvements to lung function with BFF MDI 160/10 $\mu \mathrm{g}$ began to decrease (fig. 5a and b). LOESS curves of BFF MDI 320/10 $\mu \mathrm{g}$ and BFF MDI $160 / 10 \mu \mathrm{g}$ showed that the two doses began to diverge from each other at blood eosinophil levels of approximately $350-400$ cells $\cdot \mathrm{mm}^{-3}$, with the treatment difference between the two doses exceeding $20 \mathrm{~mL}$ from approximately $450 \mathrm{cells} \cdot \mathrm{mm}^{-3}$ (fig. $5 \mathrm{c}$ ). Analysis of the rate of moderate/severe exacerbations by continuous baseline eosinophil count showed numerical improvements with both doses of BFF MDI versus FF MDI began at blood eosinophil levels of approximately $100-150$ cells $\cdot \mathrm{mm}^{-3}$ and were maintained with increasing eosinophil levels (fig. $5 \mathrm{~d}$ and e). With both BFF MDI doses, improvements in the rate of moderate or severe COPD exacerbations increased with increasing blood eosinophil levels. When plotted together, the BFF MDI doses began to diverge from each other at blood eosinophil levels of approximately $150-200$ cells $\cdot \mathrm{mm}^{-3}$, with a treatment difference between the two doses exceeding $15 \%$ at blood eosinophil levels above approximately $250-300$ cells $\cdot \mathrm{mm}^{-3}$ (fig. $5 f$ ). 

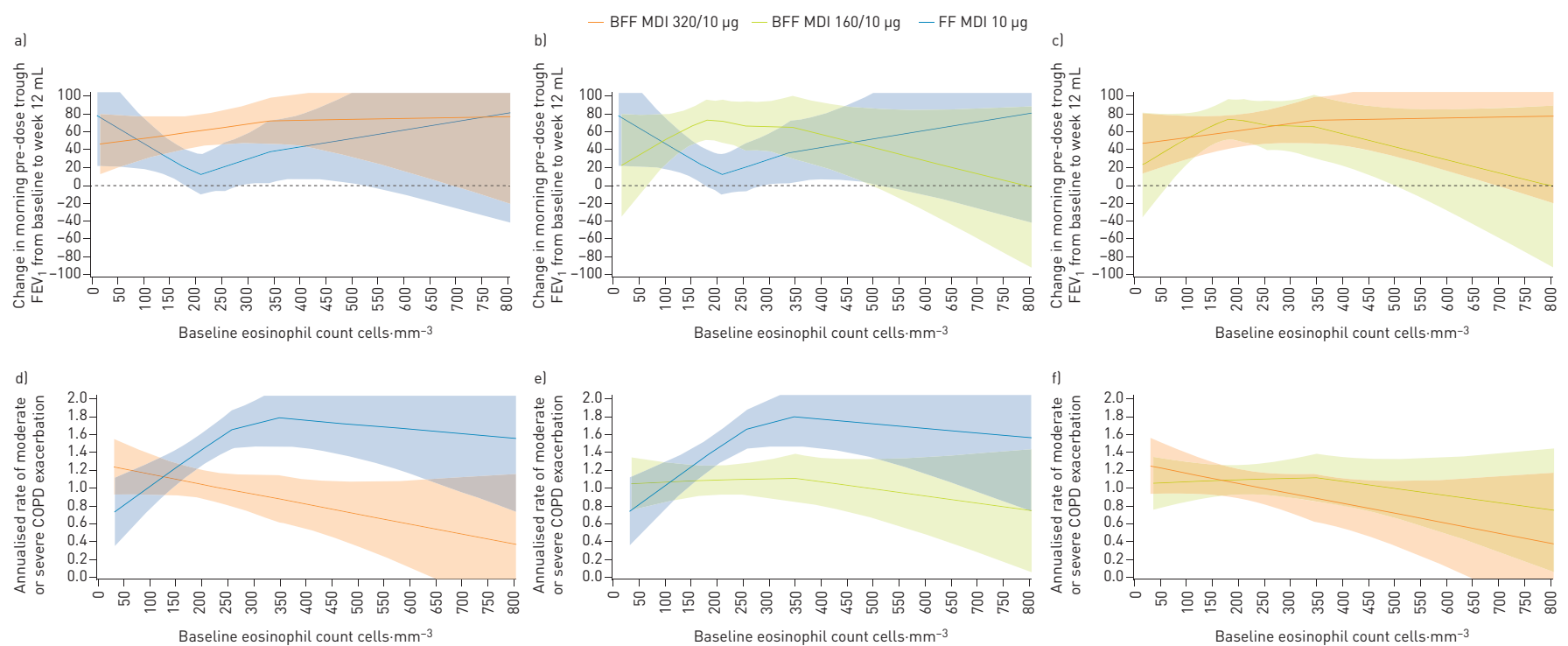

FIGURE 5 Lung function and exacerbation responses by blood eosinophil counts (efficacy estimand, modified intent-to-treat population). Change from baseline in morning pre-dose trough forced expiratory volume in $1 \mathrm{~s}\left(\mathrm{FEV}_{1}\right)(\mathrm{mL})$ at week 12 by blood eosinophil count, for a) budesonide/ formoterol fumarate dihydrate (BFF) metered dose inhaler (MDI) 320/10 $\mu \mathrm{g}$ versus formoterol fumarate dihydrate (FF) MDI 10 $\mu \mathrm{g}, \mathrm{b}$ ) BFF MDI 160/ $10 \mu \mathrm{g}$ versus FF MDI $10 \mu \mathrm{g}$, and c) BFF MDI 320/10 $\mu \mathrm{g}$ versus BFF MDI 160/10 $\mu \mathrm{g}$, and rate of moderate/severe COPD exacerbations by blood eosinophil count for d) BFF MDI 320/10 $\mu \mathrm{g}$ versus FF MDI $10 \mu \mathrm{g}$, e) BFF MDI 160/10 $\mu \mathrm{g}$ versus FF MDI $10 \mu \mathrm{g}$, and f) BFF MDI 320/10 $\mu \mathrm{g}$ versus BFF MDI 160/10 $\mu \mathrm{g}$. The banded areas represent 95\% confidence intervals. COPD: chronic obstructive pulmonary disease.

Subgroup analyses based on the number of moderate/severe exacerbations in the year before the study showed that improvements in lung function and exacerbation rates were similar in patients with a history of one moderate/severe exacerbation and those with at least two moderate/severe exacerbations (figure E3).

Post hoc analyses of the rate of moderate/severe exacerbations by ICS use prior to study entry demonstrated the benefit of ICS in all patients regardless of ICS usage prior to study entry. In an analysis that estimated the rate of exacerbations for each 4-week period, both BFF MDI doses separated from FF MDI during the first 4 months and the last 5 months of the treatment period, with some overlap during the mid-portion of the treatment period. Further details are provided in the online data supplement.

\section{Safety}

The incidence of TEAEs (table 3) was similar across treatment groups (BFF MDI 320/10 $\mu$ g, 48.0\%; BFF MDI $160 / 10 \mu \mathrm{g}, 50.9 \%$; FF MDI, 50.2\%). Most TEAEs were mild or moderate, and few patients $(4.4 \%)$ experienced a TEAE that was considered to be drug related. The incidence of serious TEAEs was highest for FF MDI (13.7\%), followed by BFF MDI 160/10 $\mu \mathrm{g}$ (12.6\%) and BFF MDI 320/10 $\mu \mathrm{g}$ (9.7\%); few serious TEAEs $(0.2 \%)$ were considered to be drug related. The incidences of TEAEs and serious TEAEs leading to study drug discontinuation were similar across the treatment groups.

There were 22 deaths in the study (15 on-treatment, i.e. due to adverse events that started during the treatment period, and seven post-treatment). The highest number of on-treatment deaths occurred in the FF MDI group ( $n=8)$, followed by BFF MDI 160/10 $\mu \mathrm{g}(\mathrm{n}=4)$ and BFF MDI 320/10 $\mu \mathrm{g}(\mathrm{n}=3)$. No deaths were considered to be drug related. Details of the causes of death are provided in the online data supplement.

The incidence of confirmed pneumonia was $1.6 \%$ in the BFF MDI $320 / 10 \mu \mathrm{g}$ group $(\mathrm{n}=10), 2.4 \%$ in the BFF MDI $160 / 10 \mu \mathrm{g}$ group $(n=15)$ and $2.3 \%$ in the FF MDI group $(n=14)$. The proportion of patients with confirmed pneumonia was lowest in the BFF MDI 320/10 $\mu \mathrm{g}$ group over all time periods $(12,24,36$ and 52 weeks; table E1). Overall, 27 patients (1.5\%) had confirmed pneumonia that was considered a serious TEAE.

Nine patients experienced TEAEs (BFF MDI $160 / 10 \mu \mathrm{g}, \mathrm{n}=3$ [0.5\%]; FF MDI, $\mathrm{n}=6$ [1.0\%]) that were confirmed as MACE (none in the BFF MDI 320/10 $\mu$ g group).

\section{Discussion}

The SOPHOS study aimed to evaluate the efficacy and safety of BFF MDI 320/10 $\mu \mathrm{g}$ and 160/10 $\mu \mathrm{g}$ in symptomatic patients with moderate-to-very severe COPD who had a prior history of COPD 


\section{TABLE 3 Treatment-emergent adverse events (TEAEs) (safety population)}

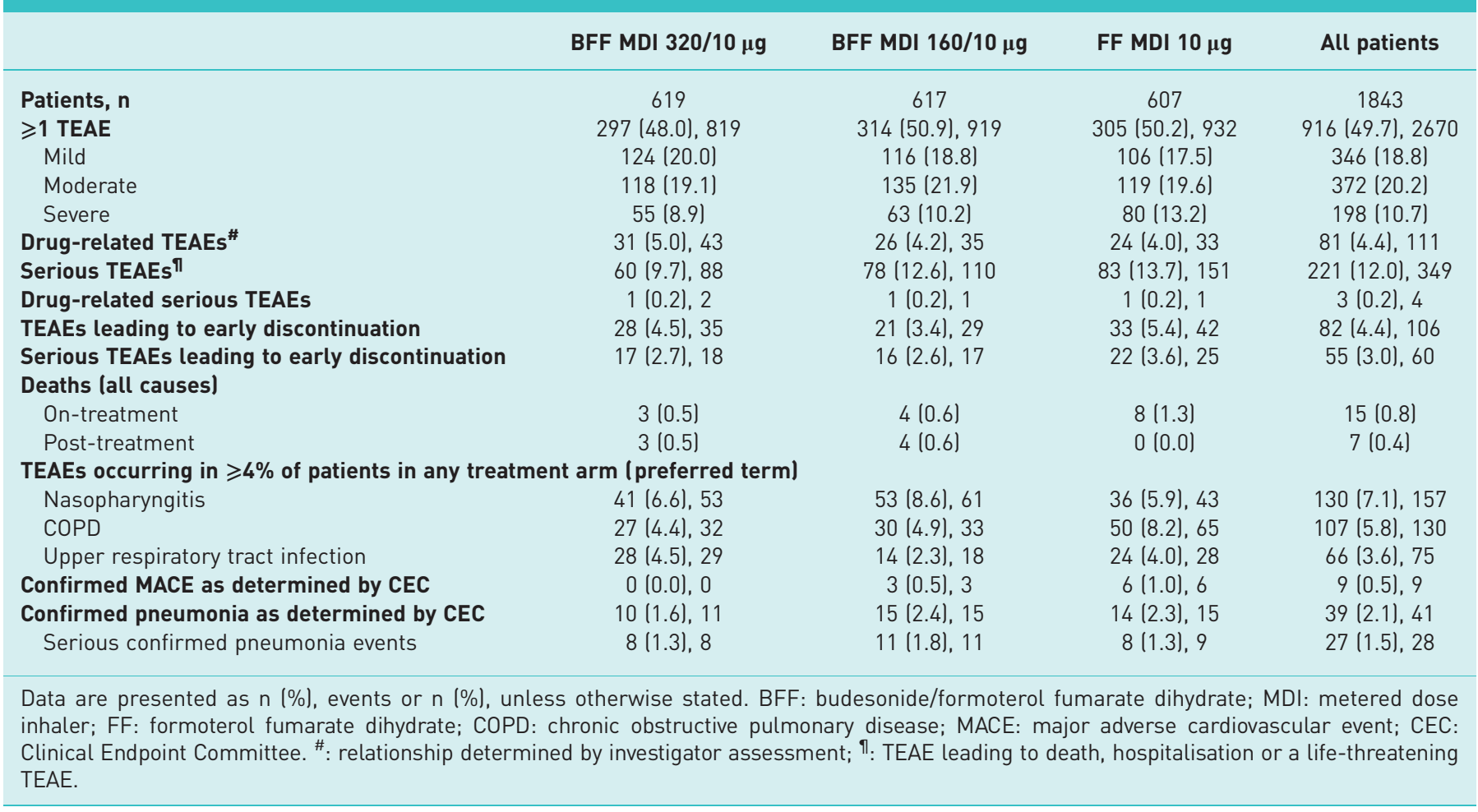

exacerbations. Both doses of BFF MDI resulted in statistically significant improvements in lung function (primary efficacy endpoint) compared with FF MDI. Also, both doses of BFF MDI resulted in significant improvements in all secondary efficacy endpoints, including time to first moderate/severe exacerbation, and both doses reduced the rate of moderate/severe exacerbations, versus FF MDI. The small numerical dose response favouring BFF MDI 320/10 $\mu \mathrm{g}$ for improvements to lung function (trough $\mathrm{FEV}_{1}$ ) and for reducing exacerbation rates in the overall study population appeared to be more pronounced as blood eosinophil levels increased, with the doses diverging above approximately 350-400 cells and 150-200 cells for trough $\mathrm{FEV}_{1}$ and exacerbation rates, respectively. Results for the Ex-US analysis approach that are provided in the online data supplement were similar to the results for the US analysis approach that are presented in this manuscript.

Our findings were well aligned with the results of TELOS (NCT02766608), a 24-week study investigating the therapeutic effects of BFF MDI $320 / 10 \mu \mathrm{g}$ and $160 / 10 \mu \mathrm{g}$ relative to treatment with monocomponents in patients with moderate-to-very severe COPD [11]. In TELOS, both doses of BFF MDI also showed superiority to FF MDI monotherapy, with a dose-related response for lung function and exacerbation endpoints. However, while $>70 \%$ of patients in TELOS did not have a moderate/severe COPD exacerbation in the year before the study, SOPHOS specifically enrolled patients with a documented history of moderate/ severe exacerbations in the year prior to the study. As expected given the differences in the patient population, the exacerbation rates in SOPHOS were considerably higher than those in TELOS, but the treatment effect of BFF MDI compared with FF MDI, as assessed by the rate ratio for COPD exacerbations, was very similar in both studies. For patients who continued treatment beyond 24 weeks and up to 52 weeks, the effects of BFF MDI on exacerbation risk seen in the first 24 weeks of treatment were sustained over the entire treatment period. Hence, SOPHOS confirmed the efficacy of BFF MDI in a population known to be at risk of exacerbations (i.e. in a population for which ICS/LABA is a recommended treatment option to prevent further exacerbations [1]) over a treatment period of 12 to 52 weeks.

A pre-defined subgroup analysis according to baseline blood eosinophil count showed that improvements in lung function and reductions in exacerbation rates were driven by patients with baseline blood eosinophil counts $\geqslant 150$ cells $\cdot \mathrm{mm}^{-3}$. These findings were generally comparable to the TELOS study [11], which included a similar eosinophil subgroup analysis. The relationship between blood eosinophil levels and response to ICS-containing therapies, with regards to reducing exacerbation risk, has also been described in other recent studies [17-21], suggesting that patients with higher eosinophil counts may 
experience greater therapeutic benefits from ICS than patients with lower eosinophil counts. Our emerging understanding of how eosinophils affect responses to ICS treatment is now also being reflected in the most recent GOLD report [1]. This recommends considering combination therapy with an ICS/LABA for patients who experience one exacerbation per year despite long-acting bronchodilator treatment if they have blood eosinophil levels $\geqslant 300$ cells $\cdot \mathrm{mm}^{-3}$, and for patients who experience two or more moderate COPD exacerbations per year (or at least one severe COPD exacerbation leading to hospitalisation) if they have eosinophil levels $\geqslant 100$ cells. $\mathrm{mm}^{-3}$. In our study, in which $61.1 \%$ of patients had one moderate/severe exacerbation in the year prior to the study (and the other $39.9 \%$ of patients had two or more), enrichment for patients with baseline blood eosinophils $\geqslant 150$ cells $\cdot \mathrm{mm}^{-3}$ allowed for a detailed analysis of lung function and exacerbations by continuous eosinophil counts. This analysis showed that with both doses, benefits on lung function and exacerbations for BFF MDI versus FF MDI were evident over a broad range of blood eosinophil levels, with numerical improvements beginning at approximately $100-150 \mathrm{cells} \cdot \mathrm{mm}^{-3}$. In addition, our analysis by continuous baseline eosinophil count showed that a dose response favouring BFF MDI 320/10 $\mu \mathrm{g}$ was evident from blood eosinophil levels of approximately $450 \mathrm{cells} \cdot \mathrm{mm}^{-3}$ for lung function endpoints and approximately $250 \mathrm{cells} \cdot \mathrm{mm}^{-3}$ for exacerbation rates. These data suggest that there is the potential for patients with COPD to derive benefit from more than one ICS dose and that overall ICS dose response is influenced appreciably by eosinophil levels. These hypotheses will be prospectively evaluated in the recently completed ETHOS study [22]. Finally, subgroup analyses based on the number of moderate/severe COPD exacerbations $(1$ or $\geqslant 2)$ in the prior year showed that the benefits on lung function and exacerbation rates for BFF MDI versus FF MDI were not affected by the number of exacerbations in the year before the study.

To minimise the potential for a run-in bias [23] patients in our study who were using ICS prior to the study entry continued the ICS during the screening period until randomisation. Additional analysis of exacerbation rates for each 4-week period of treatment indicated that the benefit of BFF MDI on exacerbations was not driven solely by acute ICS withdrawal in the first month after randomisation, as suggested for recent trials comparing triple therapy with LAMA/LABA dual therapies [24].

BFF MDI $320 / 10 \mu \mathrm{g}$ and $160 / 10 \mu \mathrm{g}$ were well tolerated in this $12-52$ week study, with no new or unexpected safety findings or dose-related effects on the pattern or frequency of TEAEs, which confirmed the findings from the 24-week TELOS study [11]. ICS use in patients with COPD has been associated with an increased risk of pneumonia $[1,25,26]$. However, there is evidence to suggest that the pneumonia risk with treatments containing budesonide may be lower compared with other ICS components [27-29], and a recent pooled analysis found no significant increase in the risk of pneumonia when comparing budesonide-containing with non-budesonide-containing treatments [30]. In the present study, the percentage of patients with confirmed pneumonia events was $2.1 \%$ overall, and lowest in the BFF MDI $320 / 10 \mu$ group (1.6\%); this was similar to the results of TELOS and also the KRONOS study, neither of which showed a higher incidence of pneumonia in their budesonide-containing treatment arms relative to non-budesonide-containing treatment arms $[11,31]$. As in the TELOS study, no ICS dose-related effect on the incidence of pneumonia was observed in this present study [11].

A potential limitation of SOPHOS was the variable length study design and the correspondingly small proportion of patients (10.2\%) who completed 52 weeks of treatment. However, the effects of BFF MDI on exacerbation risk observed in the first 24 weeks of treatment were sustained after 24 weeks, and were comparable to those observed with a different formulation of BFF versus FF over 6 months [4]. Since only a small portion of patients completed 12 months of treatment, the study may not be optimal for assessing risk of exacerbations over the long term. However, patients in this study were recruited over an 18-month period and all seasons were well represented, reducing the potential impact of seasonal variation on exacerbation rates.

In conclusion, the SOPHOS study extended the findings from the TELOS study by demonstrating the efficacy and safety of BFF MDI, formulated using co-suspension delivery technology, in the key target population for ICS/LABA treatment; i.e. patients with a history of COPD exacerbations, over a treatment period of 12 to 52 weeks. BFF MDI 320/10 $\mu \mathrm{g}$ and $160 / 10 \mu \mathrm{g}$ both improved lung function and reduced exacerbation risk compared to FF MDI monotherapy, with a dose response favouring the BFF MDI 320/ $9.6 \mu \mathrm{g}$ dose at elevated blood eosinophil levels. Both doses of BFF MDI were well tolerated, and there was no ICS dose-related effect on safety outcomes, including the incidence of confirmed pneumonia events. The study findings confirm that BFF MDI was an effective treatment for the management of COPD in patients who had a prior exacerbation history.

Acknowledgements: The authors would like to thank all the patients and their families, and the team of investigators, research nurses and operations staff involved in these studies. These data were presented at the American Thoracic Society International Conference, Dallas, TX, USA; May 2019. 
Author contributions: All authors contributed to study conception and design, and interpretation of the data. N.A Hanania, A. Papi and F.J. Martinez contributed to data acquisition. K.A. Rossman, C.S. Cappelletti, E.A. Duncan, J.S. Nyberg and P.M. Dorinsky contributed to the data analysis. All authors reviewed and provided feedback on each draft of the manuscript; approved the final draft for publication; and assume accountability for all aspects of the work.

Support statement: This study was supported by AstraZeneca. Medical writing support, under the direction of the authors, was provided by Joanna Wilson and Thomas Owens of CMC Connect, a division of McCann Health Medical Communications Ltd, Manchester, UK, funded by AstraZeneca, Gaithersburg, FL, USA in accordance with Good Publication Practice (GPP3) guidelines. Funding information for this article has been deposited with the Crossref Funder Registry.

Conflict of interest: N.A. Hanania has received personal fees for serving on advisory boards or as a consultant for AstraZeneca, Boehringer Ingelheim, GlaxoSmithKline, Mylan, Novartis, Sanofi Genzyme and Sunovion; his institution has received research grant support on his behalf from AstraZeneca, Boehringer Ingelheim and GlaxoSmithKline. A. Papi reports board membership, consultancy, payment for lectures, grants for research and travel expenses reimbursement from AstraZeneca, Boehringer Ingelheim, Chiesi, GlaxoSmithKline, Mundipharma and TEVA; payment for lectures and travel expenses reimbursement from Menarini, Novartis and Zambon; board membership, payment for lectures, grants for research and travel expenses reimbursement from Pfizer; and grants from Sanofi, outside the submitted work. A. Anzueto reports personal fees for consultancy from AstraZeneca, Boehringer Ingelheim, GlaxoSmithKline, Novartis and Sunovion Pharmaceutical; and a research grant to University of Texas Health, San Antonio, from GlaxoSmithKline, outside the submitted work. F.J. Martinez reports personal fees, nonfinancial support and other from Boehringer Ingelheim during the conduct of the study; personal fees and nonfinancial support from the American College of Chest Physicians, AstraZeneca, Boehringer Ingelheim, Canadian Respiratory Network, Chiesi, ConCert, Continuing Education, Genentech, GlaxoSmithKline, Inova Fairfax Health System, Miller Communications, the National Association for Continuing Education, Novartis, Pearl Pharmaceuticals, PeerView Communications, Physicians Education Resource, Potomac, Prime Communications, the Puerto Rican Respiratory Society, Roche, Rockpointe, Sunovion, Teva, Theravance, Unity, University of Alabama Birmingham, UpToDate, WebMD/Medscape and the Western Connecticut Health Network; nonfinancial support from Gilead, Nitto, ProterixBio and Zambon; personal fees from Academic CME, the American Thoracic Society, Columbia University, Integritas, MD Magazine, Methodist Hospital Brooklyn, New York University, Patara, PlatformIQ; other from Afferent/Merck, Bayer, Biogen, Bridge Biotherapeutics, Prometic and Veracyte; grants from the NIH, Promedior and Rare Disease Healthcare Communications. K.A. Rossman is a full-time employee of AstraZeneca. C.S. Cappelletti is a full-time employee of AstraZeneca. E.A. Duncan is a full-time employee of AstraZeneca. J.S. Nyberg is a former employee of AstraZeneca. P.M. Dorinsky is a full-time employee of AstraZeneca.

\section{References}

1 Global Initiative for Chronic Obstructive Lung Disease. 2019 Report: Global Strategy for the Diagnosis, Management and Prevention of COPD. https://goldcopd.org. Date last accessed: 28 October 2019.

2 Anzueto A, Ferguson GT, Feldman G, et al. Effect of fluticasone propionate/salmeterol (250/50) on COPD exacerbations and impact on patient outcomes. COPD 2009; 6: 320-329.

3 Calverley P, Pauwels R, Vestbo J, et al. Combined salmeterol and fluticasone in the treatment of chronic obstructive pulmonary disease: a randomised controlled trial. Lancet 2003; 361: 449-456.

4 Ferguson GT, Tashkin DP, Skärby T, et al. Effect of budesonide/formoterol pressurized metered-dose inhaler on exacerbations versus formoterol in chronic obstructive pulmonary disease: The 6-month, randomized RISE (Revealing the Impact of Symbicort in reducing Exacerbations in COPD) study. Respir Med 2017; 132: 31-41.

5 Sharafkhaneh A, Southard JG, Goldman M, et al. Effect of budesonide/formoterol pMDI on COPD exacerbations: a double-blind, randomized study. Respir Med 2012; 106: 257-268.

6 Tashkin DP, Rennard SI, Martin P, et al. Efficacy and safety of budesonide and formoterol in one pressurized metered-dose inhaler in patients with moderate to very severe chronic obstructive pulmonary disease: results of a 6-month randomized clinical trial. Drugs 2008; 68: 1975-2000.

7 Rennard SI, Tashkin DP, McElhattan J, et al. Efficacy and tolerability of budesonide/formoterol in one hydrofluoroalkane pressurized metered-dose inhaler in patients with chronic obstructive pulmonary disease: results from a 1-year randomized controlled clinical trial. Drugs 2009; 69: 549-565.

8 Calverley P, Boonsawat W, Cseke Z, et al. Maintenance therapy with budesonide and formoterol in chronic obstructive pulmonary disease. Eur Respir J 2003; 22: 912-919.

9 Fukuchi Y, Samoro R, Fassakhov R, et al. Budesonide/formoterol via Turbuhaler ${ }^{\circ}$ versus formoterol via Turbuhaler $^{\circ}$ in patients with moderate to severe chronic obstructive pulmonary disease: phase III multinational study results. Respirology 2013; 18: 866-873. 10.1111/resp.12090.

10 Szafranski W, Cukier A, Ramirez A, et al. Efficacy and safety of budesonide/formoterol in the management of chronic obstructive pulmonary disease. Eur Respir J 2003; 21: 74-81.

11 Ferguson GT, Papi A, Anzueto A, et al. Budesonide/formoterol MDI with co-suspension delivery technology in COPD: the TELOS study. Eur Respir J 2018; 52: 1801334.

12 Doty A, Schroeder J, Vang K, et al. Drug delivery from an innovative LAMA/LABA co-suspension delivery technology fixed-dose combination MDI: evidence of consistency, robustness, and reliability. AAPS PharmSciTech 2018; 19: 837-844.

13 Vehring R, Lechuga-Ballesteros D, Joshi V, et al. Cosuspensions of microcrystals and engineered microparticles for uniform and efficient delivery of respiratory therapeutics from pressurized metered dose inhalers. Langmuir 2012; 28: $15015-15023$.

14 Celli BR, MacNee W, ATS/ERS Task Force. Standards for the diagnosis and treatment of patients with COPD: a summary of the ATS/ERS position paper. Eur Respir J 2004; 23: 932-946.

15 Hankinson JL, Odencrantz JR, Fedan KB. Spirometric reference values from a sample of the general U.S population. Am J Respir Crit Care Med 1999; 159: 179-187. 
16 Centers for Disease Control and Prevention National Center for Health Statistics. Third National Health and Nutrition Examination Survey III Spirometry Procedure Manual. wwwn.cdc.gov/nchs/data/nhanes3/manuals/spiro. pdf. Date last accessed: November 82018.

17 Pascoe S, Locantore N, Dransfield MT, et al. Blood eosinophil counts, exacerbations, and response to the addition of inhaled fluticasone furoate to vilanterol in patients with chronic obstructive pulmonary disease: a secondary analysis of data from two parallel randomised controlled trials. Lancet Respir Med 2015; 3: 435-442.

18 Watz H, Tetzlaff K, Wouters EFM, et al. Blood eosinophil count and exacerbations in severe chronic obstructive pulmonary disease after withdrawal of inhaled corticosteroids: a post-hoc analysis of the WISDOM trial. Lancet Respir Med 2016; 4: 390-398.

19 Bafadhel M, Peterson S, De Blas MA, et al. Predictors of exacerbation risk and response to budesonide in patients with chronic obstructive pulmonary disease: a post-hoc analysis of three randomised trials. Lancet Respir Med 2018; 6: 117-126.

20 Yun JH, Lamb A, Chase R, et al. Blood eosinophil count thresholds and exacerbations in patients with chronic obstructive pulmonary disease. J Allergy Clin Immunol 2018; 141: 2037-2047.e2010.

21 Siddiqui SH, Guasconi A, Vestbo J, et al. Blood eosinophils: a biomarker of response to extrafine beclomethasone/ formoterol in chronic obstructive pulmonary disease. Am J Respir Crit Care Med 2015; 192: 523-525.

22 Rabe KF, Martinez FJ, Ferguson GT, et al. A Phase III study of triple therapy with budesonide/glycopyrrolate/ formoterol fumarate metered dose inhaler 320/18/9.6 $\mu \mathrm{g}$ and 160/18/9.6 $\mu \mathrm{g}$ using co-suspension delivery technology in moderate-to-very severe COPD: the ETHOS study protocol. Respir Med 2019; 158: 59-66.

23 Suissa S. Run-in bias in randomised trials: the case of COPD medications. Eur Respir J 2017; 49: 1700361.

24 Suissa S, Ariel A. Triple therapy trials in COPD: a precision medicine opportunity. Eur Respir J 2018; 52: 1801848. 10.1183/13993003.01848-2018.

25 Ernst $\mathrm{P}$, Gonzalez AV, Brassard P, et al. Inhaled corticosteroid use in chronic obstructive pulmonary disease and the risk of hospitalization for pneumonia. Am J Respir Crit Care Med 2007; 176: 162-166.

26 Calverley PMA, Anderson JA, Celli B, et al. Salmeterol and fluticasone propionate and survival in chronic obstructive pulmonary disease. N Engl J Med 2007; 356: 775-789.

27 Suissa S, Patenaude V, Lapi F, et al. Inhaled corticosteroids in COPD and the risk of serious pneumonia. Thorax 2013; 68: 1029-1036.

28 Janson C, Larsson K, Lisspers $\mathrm{KH}$, et al. Pneumonia and pneumonia related mortality in patients with COPD treated with fixed combinations of inhaled corticosteroid and long acting $\beta_{2}$ agonist: observational matched cohort study (PATHOS). BMJ 2013; 346: f3306.

29 Janson C, Stratelis G, Miller-Larsson A, et al. Scientific rationale for the possible inhaled corticosteroid intraclass difference in the risk of pneumonia in COPD. Int J Chron Obstruct Pulmon Dis 2017; 12: 3055-3064.

30 Hollis S, Jorup C, Lythgoe D, et al. Risk of pneumonia with budesonide-containing treatments in COPD: an individual patient-level pooled analysis of interventional studies. Int J Chron Obstruct Pulmon Dis 2017; 12: 1071-1084.

31 Ferguson GT, Rabe KF, Martinez FJ, et al. Triple therapy with budesonide/glycopyrrolate/formoterol fumarate with co-suspension delivery technology versus dual therapies in chronic obstructive pulmonary disease (KRONOS): a double-blind, parallel-group, multicentre, phase 3 randomised controlled trial. Lancet Respir Med 2018; 6: 747-758. 